\title{
Controlling topological entanglement in engineered protein hydrogels with a variety of thiol coupling chemistries
}

\author{
Shengchang Tang and Bradley D. Olsen* \\ Department of Chemical Engineering, Massachusetts Institute of Technology, Cambridge, MA, USA
}

\section{Edited by:}

Carissa M. Soto, Naval Research Laboratory, USA

Reviewed by:

Paola Laurienzo, Italian Research Council (CNR), Italy

Yanli Zhao, Nanyang Technological University, Singapore

*Correspondence:

Bradley D. Olsen, Department of Chemical Engineering,

Massachusetts Institute of

Technology, 77 Massachusetts

Avenue, Cambridge, MA 02139,

USA

e-mail: bdolsen@mit.edu
Topological entanglements between polymer chains are achieved in associating protein hydrogels through the synthesis of high molecular weight proteins via chain extension using a variety of thiol coupling chemistries, including disulfide formation, thiol-maleimide, thiol-bromomaleimide and thiol-ene. Coupling of cysteines via disulfide formation results in the most pronounced entanglement effect in hydrogels, while other chemistries provide versatile means of changing the extent of entanglement, achieving faster chain extension, and providing a facile method of controlling the network hierarchy and incorporating stimuli responsivities. The addition of trifunctional coupling agents causes incomplete crosslinking and introduces branching architecture to the protein molecules. The high-frequency plateau modulus and the entanglement plateau modulus can be tuned by changing the ratio of difunctional chain extender to the trifunctional branching unit. Therefore, these chain extension reactions show promise in delicately controlling the relaxation and mechanical properties of engineered protein hydrogels in ways that complement their design through genetic engineering.

Keywords: engineered protein hydrogels, coiled-coil, thiol-X click chemistries, entanglement, branching

\section{INTRODUCTION}

Control of advanced mechanical properties of hydrogels is central to their applications. In many situations, such as engineering simulant materials of articular cartilage or blood vessels (Drury and Mooney, 2003), hydrogels are required to support mechanical load and maintain structural integrity. Multiple approaches have been developed to address this issue, with emphasis on increasing the network toughness and elastic moduli, such as preparing double-networks (Gong et al., 2003; Sun et al., 2012) and fabricating composite materials (Haraguchi and Takehisa, 2002; Wang et al., 2010a). In some scenarios where dynamic properties such as injectability, self-healing, shape memory, and controlled degradation/reinforcement are desirable, non-covalent crosslinks and stimuli-responsive triggers can be incorporated into gels to fulfill the application requirements (Kloxin et al., 2009; HoltenAndersen et al., 2011; Guvendiren et al., 2012; Glassman et al., 2013). However, many methods developed in synthetic polymer systems cannot be readily applied to protein hydrogels, and manipulating the mechanical response of the gels presents a new challenge. Because the function of a protein is related to its hierarchical structure and the diversity of amino acid functional groups, site-specific and orthogonal reactions are often required to preserve protein properties in the final gel. In addition, the modification reactions can usually only be performed in aqueous buffers due to the poor solubility of proteins in organic solvents.

Currently there are two main strategies for chemically modifying proteins to manipulate the mechanical properties of protein hydrogels. The first strategy is covalently crosslinking protein polymer chains by adding crosslinking reagents (Trabbic-Carlson et al., 2003; Li et al., 2011; Chung et al., 2012), catalysts (Shen et al., 2005; Lv et al., 2010) and/or enzymes (Davis et al., 2010). As this method only modifies the amino acid residues participating in junction formation, the protein strands can retain most of their function (e.g., elasticity and stimuli responsivity). In addition, many mechanical properties at equilibrium, such as modulus and maximum swelling ratio, can be controlled by varying the dosage of the crosslinking agents according to well-known laws of hydrogel physics and network theories (Graessley, 2004; Tanaka, 2011; Kim et al., 2013). In a typical crosslinking reaction, however, the formation of network imperfections, such as dangling chains and inelastic loops, is usually uncontrollable and difficult to quantify (Zhou et al., 2012). The second strategy is coupling synthetic polymers and proteins to prepare chimeric copolymers (Jing et al., 2008; Sahin and Kiick, 2009; Wu et al., 2011; Glassman and Olsen, 2013; Glassman et al., 2013). Interactions leading to self-assembly of the polymer or protein component then create nanostructure within the hydrogel, which in some cases can be triggered by external stimuli. This method allows delicate manipulation of hydrogel mechanics, such as erosion rate, toughness and elasticity. However, preparing hybrid hydrogels adds challenges in materials synthesis and purification.

Recently, we developed a facile method for introducing entanglements into protein hydrogels through simple chain extension reactions, and we exploited this entanglement effect to engineer new mechanical responses into the materials (Tang et al., 2014). This strategy minimally modifies the protein molecules, only extending protein chains by establishing disulfide end linkages, yet it creates a drastic enhancement in many mechanical properties, including the low-frequency modulus, resistance to creep, extensibility and toughness. The disulfide linkages are redox responsive, which provides opportunities to regulate network mechanics by redox stimuli. 
In addition to disulfide coupling, several other thiol chemistries are promising candidates for coupling high molar mass proteins: thiol-maleimide, thiol-bromomaleimide and thiol-ene coupling. Thiol-maleimide chemistry enables sitespecific modification of cysteine residues and has been a popular route for constructing protein-based bioconjugates (Canalle et al., 2010; Stephanopoulos and Francis, 2011). Recently, the thiolmaleimide addition has been found to be reversible, offering new opportunities to control the degradation of the conjugates (Baldwin and Kiick, 2011). Thiol-dibromomaleimide conjugation has emerged as another important "click" chemistry (Smith et al., 2010; Jones et al., 2011; Robin et al., 2013), but only recently has its potential in the chain extension reaction been appreciated (Cui et al., 2013). The thiomaleimide adduct is redox responsive: the addition of reducing reagents such as $\beta$-mercaptoethanol (BME) reverses the reaction and recovers the unmodified proteins. Compared to other coupling chemistries, the thiol-ene reaction is the most rapid coupling method, with extremely high bimolecular rate constants in the thiyl-alkene addition, ranging from $10^{5}$ to $10^{7} \mathrm{M}^{-1} \mathrm{~s}^{-1}$ (Northrop and Coffey, 2012), which is $4-5$ orders of magnitude larger than thiol-maleimide addition (Schelté et al., 1999). Despite potential side reactions (Schöneich, 2008), there exist many successful examples demonstrating the use of thiol-ene chemistry in direct protein modification (Dondoni et al., 2009; Weinrich et al., 2010; Valkevich et al., 2012).

In this work, thiol-maleimide, thiol-bromomaleimide and thiol-ene coupling chemistries for application in protein chain extension reactions to produce entangled hydrogels are compared. In addition, the ability to use chain extension points for the modification of proteins with poly $(N$-isopropylacrylamide $)$ (PNIPAM) side chains is established, demonstrating thermally responsive mechanical behavior. By using trifunctional chain coupling agents, branched proteins are also prepared, and the effect of the ratio of di to trifunctional chain coupling agent on entanglements is assessed. These experiments demonstrate sophisticated control of molecular structure and network mechanics in engineered protein hydrogels, yielding the ability to control chain topology, chain entanglement, and chemical functionalization all through thiol-based chain coupling chemistries.

\section{MATERIALS AND METHODS MATERIALS}

Bismaleimide diethylene glycol (1a) was purchased from Thermo Fischer. Maleimide-PEG(1k)-maleimide (1b) was purchased from creative PEGWorks. The average molecular weight of the PEG portion determined by ${ }^{1} \mathrm{H}$ NMR was $1082 \mathrm{Da}$. $\beta$-cyclodextrin $(\beta C D)$ and 2,2'-Azobis[2-(2-imidazolin-2-yl) propane]dihydrochloride (VA-044) were purchased from Wako USA. All other chemical reagents were purchased from commercial sources (Sigma-Aldrich and VWR) and used as received unless otherwise noted.

\section{CHARACTERIZATION}

${ }^{1} \mathrm{H}$ NMR spectra were recorded in $\mathrm{CDCl}_{3}$ or DMSO- $d_{6}$ using a Varian Mercury $300 \mathrm{MHz}$ Spectrometer in Department of
Chemistry Instrumentation Facilities at MIT. High-resolution mass spectrometry (HRMS) data was obtained on a Bruker Daltonics APEXIV 4.7 Tesla Fourier Transform Ion Cyclotron Resonance Mass Spectrometer. Matrix assisted laser desorption ionization mass spectrometry (MALDI) data was obtain on a Bruker Omniflex MALDI-TOF Mass Spectrometer. $\alpha$-Cyano-4hydroxycinnamic acid (CHCA) was used as matrix. Gel permeation chromatography (GPC) was performed on an Agilent 1260 system equipped with a Wyatt Optilab T-rEX refractive index (RI) detector and a Wyatt Mini-DAWN multi-angle light scattering (LS) detector. The mobile phase was DMF supplemented with $0.02 \mathrm{M} \mathrm{LiBr}$ and the instrument was operated at $1.0 \mathrm{~mL} / \mathrm{min}$ at $70^{\circ} \mathrm{C}$.

\section{PROTEIN Cys-P 4 -Cys EXPRESSION AND PURIFICATION}

Protein expression and purification by ammonium sulfate purification have been described previously (Tang et al., 2014). In this study, the proteins were additionally purified by anion exchange chromatography using a HiTrap Q Sepharose HP $5 \mathrm{~mL}$ column (GE healthcare, WI), eluting with a gradient of $0-500 \mathrm{mM} \mathrm{NaCl}$ in $6 \mathrm{M}$ urea and $20 \mathrm{mM}$ Tris ( $\mathrm{pH} \mathrm{8.0)}$. A typical isolation yield is $120 \mathrm{mg}$ per liter culture and the protein purity was determined to be $>97 \%$ by sodium dodecyl sulfate-polyacrylamide gel electrophoresis (SDS-PAGE).

\section{CHEMICAL COMPOUND SYNTHESIS Dibromomaleimide-alkyne}

The synthesis procedure reported elsewhere (Jones et al., 2011) was slightly modified. Potassium carbonate $(0.89 \mathrm{~g}, 6.50 \mathrm{mmol})$ was suspended in $20 \mathrm{~mL}$ acetone and 2,3-dibromomaleimide $(1.5 \mathrm{~g}, 5.90 \mathrm{mmol})$ was added to the slurry in one portion and the reaction was left to stir at room temperature for $5 \mathrm{~min}$. Propargyl bromide ( $80 \%$ in toluene, $0.72 \mathrm{~mL}, 6.50 \mathrm{mmol}$ ) was added dropwise to the mixture over $10 \mathrm{~min}$. After $24 \mathrm{~h}$, solvent was removed under vacuum and the mixture was redissolved in DCM. Salts were filtered and the residue was loaded onto a silica gel column vacuum. The crude product was purified by flash chromatography, eluted with $0-2 \% \mathrm{MeOH}$ in DCM (TLC $R_{f}=0.78$, stained with $\mathrm{KMnO}_{4}$ solution) to afford $492 \mathrm{mg} 4$ as a white powder (yield 28.5\%).

${ }^{1} \mathrm{H} \mathrm{NMR}\left(300 \mathrm{MHz}, \mathrm{CDCl}_{3}\right) \delta 4.38(\mathrm{~d}, J=2.4 \mathrm{~Hz}, 2 \mathrm{H}), 4.83$ $(\mathrm{t}, J=2.4 \mathrm{~Hz}, 1 \mathrm{H})$. DART HRMS $(\mathrm{m} / \mathrm{z})$ calcd for $\mathrm{C}_{7} \mathrm{H}_{4} \mathrm{Br}_{2} \mathrm{NO}_{2}$ $[\mathrm{M}+\mathrm{H}]^{+}:$293.8586; found 293.8585 .

\section{Dibromomaleimide- $\beta$-CD}

To a $25 \mathrm{~mL}$ Schlenk tube was added $4(58.5 \mathrm{mg}, 0.20 \mathrm{mmol})$, mono-6-deoxy-6-azido- $\beta$-cyclodextrin (Petter et al., 1990) (116.0 mg, $0.10 \mathrm{mmol}), \mathrm{Cu}(\mathrm{I}) \mathrm{Br}(14.3 \mathrm{mg}, 0.10 \mathrm{mmol})$ and $5 \mathrm{~mL}$ DMF. The mixture was degassed through 3 freeze-pump-thaw cycles. $2,2^{\prime}$-Bipyridine $(15.6 \mathrm{mg}, 0.10 \mathrm{mmol})$ was added to the frozen mixture and the mixture was degassed one more time. The click reaction was performed at $30^{\circ} \mathrm{C}$ for $24 \mathrm{~h}$. Catalyst was removed by passing through a short alumina column and the product was obtained by precipitation in acetone twice to get $63 \mathrm{mg} 2$ as a yellow powder (yield 43.4\%).

${ }^{1} \mathrm{H}$ NMR $\left(300 \mathrm{MHz}, \mathrm{DMSO}-d_{6}\right) \delta 8.06(\mathrm{~s}, 1 \mathrm{H}), 5.95-5.60$ $(\mathrm{m}, 14 \mathrm{H}), 5.10-4.67(\mathrm{~m}, 9 \mathrm{H}), 4.65-4.42(\mathrm{~m}, 6 \mathrm{H}), 3.79-3.48$ 
(m, 28H), 3.43-3.21 (m, overlaps with HOD). MALDI-TOF MS $(\mathrm{m} / \mathrm{z})$ calcd for $\mathrm{C}_{49} \mathrm{H}_{72} \mathrm{Br}_{2} \mathrm{~N}_{4} \mathrm{O}_{3} \mathrm{Na}[\mathrm{M}+\mathrm{Na}]^{+}$: 1473.22; found 1473.22.

\section{Bisallyl tetraethylene glycol}

Tetraethylene glycol $(5.0 \mathrm{~g}, 25.7 \mathrm{mmol})$ was dissolved in $30 \mathrm{~mL}$ anhydrous DMF. Sodium hydride $(3.5 \mathrm{~g}, 60 \%$ in mineral oil, $87.5 \mathrm{mmol}$ ) was added to the mixture in one portion. The mixture was cooled with a water bath and allowed to stir for $30 \mathrm{~min}$ at room temperature. After the reaction stopped bubbling, allyl bromide $(9.5 \mathrm{~g}, 78.4 \mathrm{mmol})$ was added dropwise. After $14 \mathrm{~h}$, excess $\mathrm{NaH}$ was quenched by adding $10 \mathrm{~mL}$ saturated $\mathrm{NH}_{4} \mathrm{Cl}$ aqueous solution. The mixture was diluted with EtOAc, washed with DI water and brine, and dried over $\mathrm{MgSO}_{4}$. Then solvent was removed under reduced pressure. The crude product was purified by silica gel column chromatography, eluted with $50 \%$ EtOAc in hexanes (TLC $R_{f}=0.41$, stained with $\mathrm{KMnO}_{4}$ solution) to afford $3.65 \mathrm{~g} 3$ as a slightly yellow liquid (yield $51.8 \%)$.

${ }^{1} \mathrm{H}$ NMR $\left(300 \mathrm{MHz}, \mathrm{CDCl}_{3}\right) \delta 5.91(\mathrm{~d} \times \mathrm{d} \times \mathrm{t}, J=17.1 \mathrm{~Hz}$, $\left.J=10.5 \mathrm{~Hz},{ }^{3} J=5.7 \mathrm{~Hz}, 2 \mathrm{H}\right), 5.27(\mathrm{~d} \times \mathrm{d} \times \mathrm{t}, J=17.1 \mathrm{~Hz}$, $J=1.5 \mathrm{~Hz}, J=1.5 \mathrm{~Hz}, 2 \mathrm{H}), 5.18(\mathrm{~d} \times \mathrm{d} \times \mathrm{t}, J=17.1 \mathrm{~Hz}, J=$ $1.8 \mathrm{~Hz}, J=1.2 \mathrm{~Hz}, 2 \mathrm{H}), 4.02(\mathrm{~d} \times \mathrm{t}, J=5.7 \mathrm{~Hz}, J=1.5 \mathrm{~Hz}, 4 \mathrm{H})$, 3.68-3.58 (m, 16H). DART HRMS $(\mathrm{m} / \mathrm{z})$ calcd for $\mathrm{C}_{14} \mathrm{H}_{27} \mathrm{O}_{5}$ $[\mathrm{M}+\mathrm{H}]^{+}: 275.1853$; found 275.1851 .

\section{EMP-Adamantane (EMP-Ad)}

The synthesis of 2-ethylsulfanylthiocarbonylsulfanyl-2-methylpropionic acid (EMP) was performed as previously reported (Lai et al., 2002; Convertine et al., 2006). To a $25 \mathrm{~mL}$ round bottom flask was added EMP (179.5 mg, $0.80 \mathrm{mmol}), 1$-adamantane methanol (159.6 mg, $0.96 \mathrm{mmol}), \quad 4$-dimethylaminopyridine (DMAP) $(19.5 \mathrm{mg}, 0.16 \mathrm{mmol})$ and $5 \mathrm{~mL}$ DCM. After all reagents were dissolved, $N, N^{\prime}$-dicyclohexylcarbodiimide (DCC) $(247.6 \mathrm{mg}, 1.20 \mathrm{mmol})$ was added in one portion. The reaction mixture was stirred at room temperature overnight. The precipitate was filtered and the solvent was removed under vacuum. The crude product was purified by silica gel column chromatography, eluted with $30 \%$ DCM in hexanes (TLC $R_{f}=0.30$, yellow or stained with $\mathrm{KMnO}_{4}$ solution) to afford $210 \mathrm{mg} \mathbf{5}$ as a bright yellow solid (yield 70.5\%).

${ }^{1} \mathrm{H} \mathrm{NMR}\left(300 \mathrm{MHz}, \mathrm{CDCl}_{3}\right) \delta 3.60(\mathrm{~s}, 2 \mathrm{H}), 3.25(\mathrm{q}, J=$ $7.5 \mathrm{~Hz}, 2 \mathrm{H}), 1.93(\mathrm{~s}, 3 \mathrm{H}), 1.71-1.60(\mathrm{~m}, 12 \mathrm{H}), 1.49(\mathrm{~d}, J=$ $2.4 \mathrm{~Hz}, 6 \mathrm{H}), 1.28(\mathrm{~d}, J=7.5 \mathrm{~Hz}, 3 \mathrm{H})$. ESI HRMS $(\mathrm{m} / \mathrm{z})$ calcd for $\mathrm{C}_{18} \mathrm{H}_{28} \mathrm{O}_{2} \mathrm{~S}_{3}[\mathrm{M}+\mathrm{H}]^{+}$: 373.1343 ; found 373.1324 .

\section{PNIPAM-Ad}

$N$-isopropyl acrylamide (NIPAM) was freshly purified by sublimation and azobisisobutyronitrile (AIBN) was recrystallized twice from ethanol. In polymerization, NIPAM $(1.09 \mathrm{~g}$, $9.6 \mathrm{mmol})$, EMP-Ad $(29.8 \mathrm{mg}, 0.080 \mathrm{mmol})$, AIBN $(2.63 \mathrm{mg}$, $0.016 \mathrm{mmol}$ ) and $4.8 \mathrm{~mL}$ acetonitrile were added to a $25 \mathrm{~mL}$ Schlenk tube. The reaction mixture was subjected to 3 cycles of freeze-pump-thaw to degas oxygen. The reaction was heated at $60^{\circ} \mathrm{C}$ for $4 \mathrm{~h}$, after which polymers were recovered by precipitation in diethyl ether. The molar mass of the obtained polymer was $7.8 \mathrm{~kg} / \mathrm{mol}$ (from GPC, dispersity $Ð=1.05$ ), $7.4 \mathrm{~kg} / \mathrm{mol}$ (from
${ }^{1} \mathrm{H}$ NMR endgroup analysis) and $7.0 \mathrm{~kg} / \mathrm{mol}$ (from MALDI-TOF MS), respectively.

\section{EXTENDING PROTEIN CHAINS USING DIFFERENT CYSTEINE COUPLING CHEMISTRIES (INCLUDING BRANCHING REACTIONS) \\ Thiol-maleimide}

Protein Cys- $\mathrm{P}_{4}$-Cys was dissolved in denaturing buffer ( $8 \mathrm{M}$ urea and $100 \mathrm{mM}$ phosphate, $\mathrm{pH} 8.0$ ) to reach a concentration of $10 \%$ (w/v). Tris(2-carboxyethyl)phosphine (TCEP) (20 eq.) was added to the solution and the $\mathrm{pH}$ was adjusted to 7.5. Bismaleimide $\mathbf{1 a}$ or $\mathbf{1 b}$ was dissolved in DMF, and was added to the solution ( 1 eq.). The reaction was stirred at room temperature for 3 days, and it was then dialyzed against MilliQ water and lyophilized. The long reaction time was chosen based on experimental results to maximize endgroup conversion and entanglement in gels.

\section{Thiol-bromomaleimide}

Protein Cys- $\mathrm{P}_{4}$-Cys was dissolved in denaturing buffer ( $8 \mathrm{M}$ urea and $100 \mathrm{mM}$ phosphate, $\mathrm{pH} 8.0$ ) to reach a concentration of $10 \%$ $(\mathrm{w} / \mathrm{v})$. TCEP (20 eq.) was added to the solution and the $\mathrm{pH}$ was adjusted to 6.2. $\beta \mathrm{CD}$ functionalized dibromomaleimide 2 was dissolved in DMSO, and was added to the solution (1 eq.). The reaction was stirred at $4^{\circ} \mathrm{C}$ for 7 days, and it was then dialyzed against MilliQ water and lyophilized.

\section{Thiol-ene}

Protein Cys- $\mathrm{P}_{4}$-Cys was dissolved in denaturing buffer ( $8 \mathrm{M}$ urea and $100 \mathrm{mM}$ phosphate, $\mathrm{pH} 8.0$ ) to reach a concentration of $10 \%$ $(\mathrm{w} / \mathrm{v})$. TCEP (20 eq.) was added to the solution. The mixture was left to stir at room temperature for $4 \mathrm{~h}$, and it was then dialyzed against MilliQ water and lyophilized. After reduction, $>99 \%$ of the proteins were in the monomeric state, assessed by SDS-PAGE (Supplementary Figure 2). Reduced proteins were hydrated in $100 \mathrm{mM}$ sodium phosphate buffer ( $\mathrm{pH} 7.6$ ), and mixed with 3 ( 1 eq.) and VA-044 (0.2 eq.). The final concentration was adjusted to $20 \%(\mathrm{w} / \mathrm{v})$. Hydrogel samples were loaded on the rheometer after hydration for 2 days. The reaction was triggered by heating at $60^{\circ} \mathrm{C}$ for $3 \mathrm{~h}$. The moduli were monitored at $25^{\circ} \mathrm{C}$ to ensure that the steady state was reached before measurement.

In branching reactions, the trifunctional crosslinker 2,4,6triallyloxy-1,3,5-triazine 6 was used in place of the bifunctional crosslinker 3. The total number of alkene groups was kept in 1:1 molar ratio to thiol groups, while the amount of $\mathbf{6}$ was varied from $0-100 \%$ of the total mole fraction of alkene-containing oligomer.

\section{RHEOLOGY}

Rheology experiments were performed on Anton Paar MCR 301,501 , and 702 rheometers using a cone and plate geometry $\left(25 \mathrm{~mm}\right.$ diameter, $1^{\circ}$ cone and $50 \mu \mathrm{m}$ truncation gap) or a parallel plate geometry ( $10 \mathrm{~mm}$ diameter and $300 \mu \mathrm{m}$ gap, only for measurement with $\beta C D$-functionalized protein hydrogels). The quantitative measurement of hydrogel mechanics was not affected by the choice of rheometers. Lyophilized proteins were hydrated in $100 \mathrm{mM}$ sodium phosphate buffer $(\mathrm{pH} 7.6)$ to a final concentration of $20 \%(\mathrm{w} / \mathrm{v})$. Hydrogels were kept at $4^{\circ} \mathrm{C}$ for 2 days to allow complete hydration. In order to minimize dehydration during measurement, the edges of hydrogel samples 
were coated with mineral oil. After loading onto the rheometer, samples were heated from $25^{\circ} \mathrm{C}$ to $90^{\circ} \mathrm{C}$ and cooled to $25^{\circ} \mathrm{C}$ at $5^{\circ} \mathrm{C} / \mathrm{min}$. Unfolding of the coiled-coil domains at high temperatures allowed rapid stress relaxation within the gel to eliminate any shear history, but no sol-gel transition was observed over this temperature range (Supplementary Figure 1). Frequency sweep measurements were performed at $1 \%$ strain in the linear viscoelastic regime (LVE). In creep experiments, a $25 \mathrm{~Pa}$ load was exerted on hydrogels for $2 \mathrm{~h}$, and the load was removed to monitor the recovery behavior for $2 \mathrm{~h}$. The creep-recovery experiment was repeated at $50 \mathrm{~Pa}$ load to ensure the deformation was independent of the applied load.

\section{RESULTS AND DISCUSSION \\ COMPARISON OF VARIOUS CHEMISTRIES ON THE CHAIN EXTENSION REACTION}

Chain extension of cysteine end-capped proteins can be achieved by applying thiol-maleimide, thiol-bromomaleimide and thiolene coupling chemistries under appropriate reaction conditions
(Scheme 1 and Figure 1). All chemistries require reduction of existing disulfides to recover reactive cysteine residues. In order to achieve significant changes in mechanical properties, the conversion of these macromolecular polycondensation reactions must be relatively high to produce proteins of high molecular weights. In practice, this is achieved by controlling stoichiometry of the reacting species. A theoretical full conversion of endgroups can only be obtained when the ratio of cysteines to alkenes is $1: 1$. Running the reaction for extended periods is also useful to reach high conversions.

Each chemistry offers its own distinct advantages and disadvantages for chain extension. In the thiol-maleimide reaction, $\mathrm{pH}$ control is critical to minimize amine-maleimide coupling while achieving fast conjugation (Hermanson, 2008). In addition, dimaleimide reagents are commercially available with varying distance between the two maleimide groups, and this spacer length may affect the polycondensation reaction due to their subtle differences in solubility or by altering the propensity to form bridges or primary loops (Dutton et al., 1994). To study the effect of the
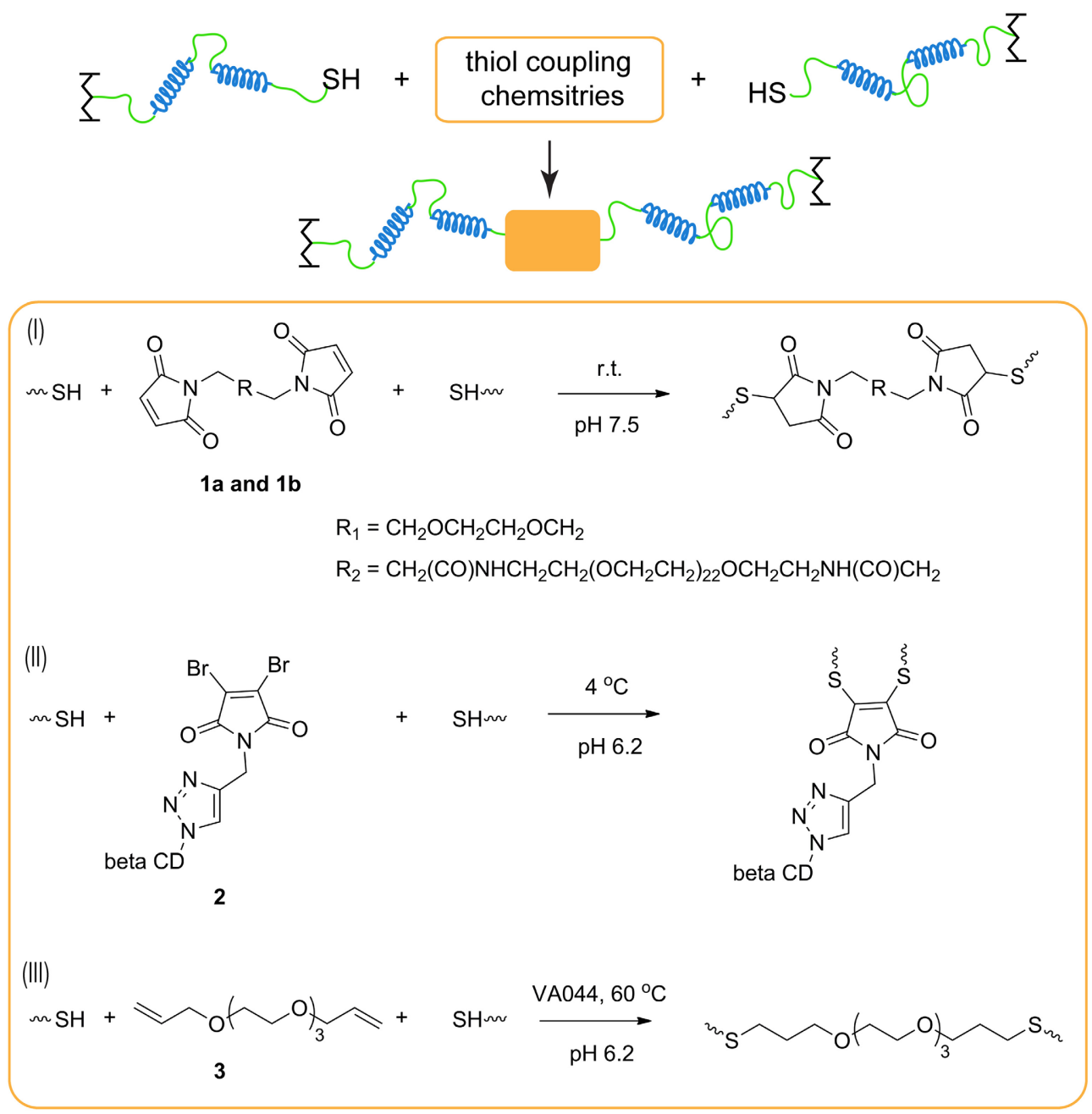

Scheme 1 | Cysteine coupling chemistries to extend protein chains. (I) Thiol-maleimide conjugation; (II) thiol-dibromomaleimide conjugation; and (III) thiol-ene chick chemistry. 


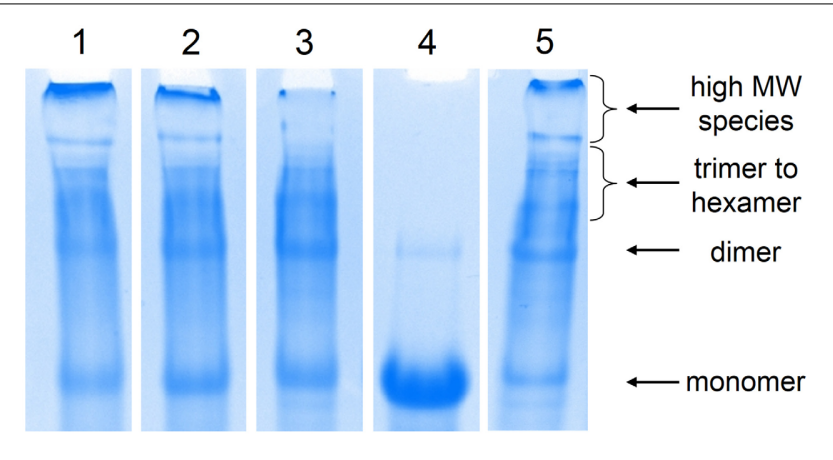

FIGURE 1 | Analysis of the chain extension products by SDS-PAGE.

Lane 1: thiol-maleimide with 1a; lane 2: thiol-maleimide with 1b; lane 3 : thiol-dibromomaleimide; lane 4: reduction of chain-extended proteins by BME; lane 5: thiol-ene. The abundance of high molecular weight species in thiol-ene and thiol-maleimide corresponds to their higher entanglement plateau.

distance between two conjugation sites, bismaleimide with two different oligo ethylene glycol spacer lengths $\mathbf{1 a}$ and $\mathbf{1} \mathbf{b}$ are used to conduct chain extension. It is found that the spacer length does not greatly affect the chain extension when the coupling reagents can be solubilized and homogeneously dispersed in the reaction.

As for thiol-dibromomaleimide coupling, controlling the hydrolysis of the maleimide ring, especially the monothio adduct, is crucial to attain significant chain extension. If hydrolysis happens on the dithio adduct, transformation from maleimide to maleamic acid does not affect chain extension, and it only results in loss of the reversibility of the thiomaleimide adduct (Supplementary Scheme 1). In contrast, hydrolysis of the monothio adduct can potentially limit the conversion, as the number of reactive bromomaleimide functional group decreases (Supplementary Scheme 1). Maleimide hydrolysis can be regulated in many ways, including changing temperature, $\mathrm{pH}$ (Ryan et al., 2011) and the electron density distribution in the maleimide structure (Nathani et al., 2013). In our hands, the first two parameters are optimized: a low temperature $\left(4^{\circ} \mathrm{C}\right)$ and a slightly acidic buffer condition ( $\mathrm{pH}$ 6.2) are chosen to be the reaction condition, under which moderate chain extension is achieved. After chain extension, the protein is exposed to 1000-fold excess BME, and $\sim 98 \%$ of the proteins are converted to the monomeric state (Figure 1), which demonstrates the reversibility of the dithiomaleimide adduct.

In the thiol-ene coupling strategy, bis allyl compound $\mathbf{3}$ is chosen as the chain extender to prevent homopolymerization of alkenes that can occur when (meth)acrylate groups are used (Hoyle and Bowman, 2010), and water soluble VA-044 is selected as the thermal initiator for its low decomposition temperature. As the thiol-ene reaction is tolerant of oxygen (Hoyle et al., 2010), no cumbersome degassing procedure is required, enabling its convenient use in applications. Upon heating at $60^{\circ} \mathrm{C}$ for $3 \mathrm{~h}$, a large fraction of high-molecular-weight proteins is formed. While thermally initiated chain extension is used here in order to ensure homogeneous reaction through a concentrated solution, it is also possible to perform photoinitiated chain extension using this chemistry, especially in occasions when spatial and temporal control of gel mechanics is required. TCEP needs to be removed prior to the thiol-ene reaction; otherwise the degree of chain extension is fairly low (Supplementary Figure 2). The deleterious effect of TCEP may be due to the desulfurization of cysteines catalyzed by TCEP during free-radical-based reactions, an effect that has been observed under similar reaction conditions (Wan and Danishefsky, 2007).

Cysteine coupling chemistries exhibit different performances in the chain extension reaction, and the differences in the molecular weight distribution of the chain-extended proteins result in varying extents of entanglement in the protein hydrogels. As shown in Figure 2, hydrogels prepared via different chemistries all show an entanglement plateau modulus in the low-frequency regime. The chain molar mass distributions extracted from gels in Figure $\mathbf{1}$ do not fit well to the Jacobson-Stockmayer distribution, likely because of challenges in controlling stoichiometry of reagents in small samples and because of difficulty in quantitatively separating the large high molar mass band, which contains a mix of proteins with a molar mass of ca. $380 \mathrm{~kg} / \mathrm{mol}$ and above (6-mers and above). Therefore, the chain extension and the entanglement effect is quantitatively analyzed by the entanglement plateau moduli in the low frequency regime. The apparent entanglement molecular weight $M_{e}$ can be estimated as (Larson et al., 2003)

$$
M_{e}=\frac{4}{5} \frac{\rho \varphi R T}{G_{e}}
$$

with $\rho$ being the protein density, $\varphi$ the protein volume fraction in the gel, $R$ the gas constant, $T$ the absolute temperature and $G_{e}$ the entanglement plateau modulus. Although the entanglement plateau modulus should not depend on the molecular weight of the protein polymers in the high molecular weight limit, proteins formed via macromolecular polycondensation show very broad molecular weight distributions with a certain fraction of the protein chains below the critical entanglement length. These "small" proteins act as macromolecular diluents and lower the effective concentration of the entangled species, consistent with the concentrations investigated being in the transition from the sticky Rouse phase to the sticky reptation regime (Tang et al., 2014). Therefore, increasing chain molecular weight, particularly the low molar mass tail, can increase $M_{e}$. Consequently, differences in the degree of chain extension will yield differences in the plateau modulus of gels.

Compared to disulfide bridging investigated previously (Tang et al., 2014), the three chemistries examined here show lower degrees of chain extension. $G_{e}$ and $M_{e}$ are compared in Figures 3A,B. For 20\% (w/v) hydrogels, disulfide coupling leads to a $G_{e}$ of around $8800 \mathrm{~Pa}$, approximately 2-8 times larger than the $G_{e}$ 's from other chemistries. As a result, $M_{e}$ is only $55 \mathrm{~kg} / \mathrm{mol}$ in the disulfide coupling, even smaller than the molecular weight of a monomeric protein. The reasons for the lower entanglement molar masses in disulfide coupling are two-fold. First and most importantly, the stoichiometric imbalance between alkenes and thiols, due to inevitable experimental errors, set a practical limit of the functional group conversion in the $\mathrm{A}-\mathrm{A}+\mathrm{B}-\mathrm{B}$ type macromolecular polycondensation that becomes more acute 


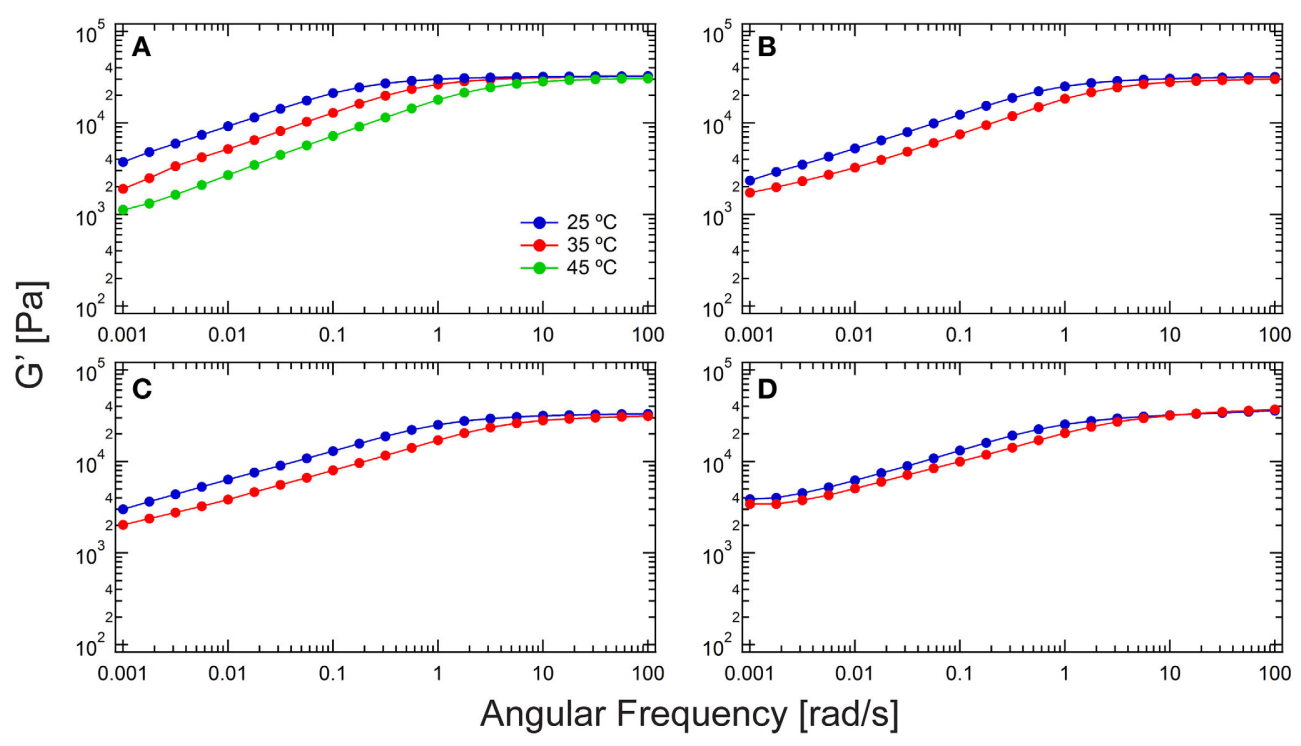

FIGURE 2 | Comparison of rheological frequency sweeps of chain extended hydrogels from various chemistries. (A) Thiol-maleimide with 1a; (B) thiol-maleimide with 1b; (C) thiol-dibromomaleimide; and (D) thiol-ene.
The plateau modulus in the low frequency regime down to $0.001 \mathrm{rad} / \mathrm{s}$ is the entanglement plateau. The frequency spectrum shifts to the high-frequency end at elevated temperatures.
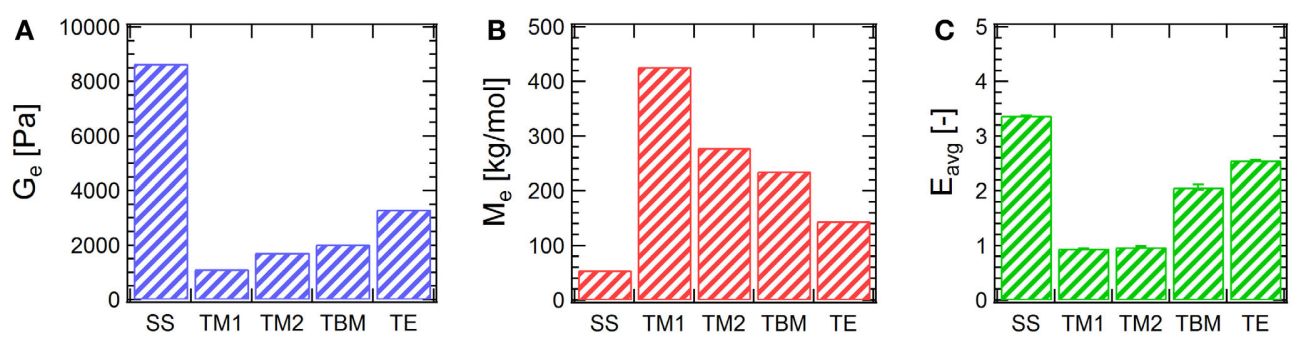

FIGURE 3 | Comparison of (A) entanglement plateau moduli, (B) the apparent entanglement molecular weights, and (C) the average entanglement densities. SS: disulfide, data from Tang et al. (2014); TM1, thiol-maleimide with 1a; TM2, thiol-maleimide with 1b; TBM, thioldibromomaleimide; TE, thiol-ene. Error bars represent a $95 \%$ confidence interval. for chemistry performed on small samples. On the contrary, the disulfide bridging chemistry has no theoretical limit in the degree of chain extension due to stoichiometry since it is an A-A type polycondensation. Second, there are various side reactions in thiol-maleimide, thiol-bromomaleimide and thiol-ene coupling, which limit their ability to reach full conversion. As mentioned previously, the primary concern is that the occurrence of side reactions may reduce the availability of the reactive functional groups (e.g., maleimide hydrolysis) or cause uncontrolled chain coupling (e.g., amine-maleimide coupling). These side reactions further exacerbate challenges in controlling the stoichiometry of A and $\mathrm{B}$ reactive groups in the macromolecular polycondensation. $G_{e}$ not only provides clues to analyze the extent of entanglement, but also provides information on the effect of side reactions. The difference in $G_{e}$ might indicate that fewer side reactions occur in the thiol-ene coupling in the three chemistries examined in the study. Interestingly, although coupling with 2 only reaches moderate chain extension and side reactions might have the most detrimental effect, $G_{e}$ from thiol-bromomaleimde coupling is larger those from thiolmaleimide chemistries. It is hypothesized that the supramolecular association between $\beta C D$ and amino acid residues forms weak and dynamic crosslink junctions (with equilibrium constant $\log K$ around 2-3) (Rekharsky and Inoue, 1998), thus increasing the modulus in the low-frequency regime.

Creep experiments also provides information to compare the entanglement effects in gels prepared by different chemistries. Here, entanglement density $E$ is used to quantify the entanglement effect, a quantity defined as the number of entanglements per molecule, namely, $E=M / M_{e}$ (Graessley, 2008). Strictly speaking, the definition above is used to describe the extent of entanglement of monodisperse polymers. Here the concept is borrowed to provide an estimate of the number-averaged entanglement density. In the low $E$ limit (when $E<6$ ), the average entanglement density in the chain extended protein mixtures can be calculated as

$$
E_{\text {avg }}=2.5 J_{e}^{0} G_{e}
$$


where $J_{e}^{0}$ is the recoverable compliance, calculated as the extrapolated intercept from a linear fit in steady state of the $J$ - $t$ data (Supplementary Figure 3); $G_{e}$ is the entanglement plateau modulus, as defined by Graessley (2008) differently than the definition by Larson et al. shown above by a factor of $4 / 5$. As shown in Figure 3C, the low $E$ values confirm the previous assumption that the entanglement density is not large. It is also found that the average entanglement densities of the chain-extended proteins gives the same trend as the entanglement plateau moduli in gels, namely, disulfide $>$ thiol-ene $>$ thiol-bromomaleimide $>$ thiol-maleimide. For entangled gels prepared via thiol-maleimide coupling, $E_{\text {avg }}$ is only approximately unity. On the contrary, $E_{\text {avg }}$ is larger than 3 for gels prepared via disulfide bridging.

Because dibromomaleimide can be readily functionalized, dibromomaleimide coupling provides a facile method of incorporating biological niches into the hydrogel network and embedding additional stimuli triggers to manipulate network structure. To illustrate this concept, dibromomaleimide is first derivatized with alkyne, and is further functionalized with $\beta C D$ through copper-catalyzed azide-alkyne cycloaddition (CuAAC) to obtain 2 (Scheme 2). $\beta C D$ is chosen because its internal cavity can host many small guest molecules, such as drugs, via hydrogen bonding and hydrophobic interactions (Davis and Brewster, 2004). The most widely used complexation pair is $\beta C D$-adamantane with an association constant $K_{a}$ of about $5 \times 10^{4} \mathrm{M}^{-1}$ (Harries et al., 2005). This supramolecular association may offer modification sites to attach functionalities to the protein backbone. Here, the $\beta C D$-adamantane host-guest interaction is used to demonstrate the ability to add thermoreversible association to hydrogels. Adamantane end-capped monodisperse PNIPAM is synthesized by reversible addition-fragmentation chain transfer (RAFT) polymerization using trithiocarbonate $\mathbf{5}$ as the RAFT agent (Supplementary Figure 4), and the polymer's endgroup structure is confirmed by MALDI-TOF and NMR (Supplementary Figures 5,6 , respectively). Upon complexation, the hybrid structure is hypothesized to adopt a graft-like structure: the chain-extended protein serves as backbone while the thermoresponsive polymers PNIPAM graft as side chains (Figure 4). Under the experimental

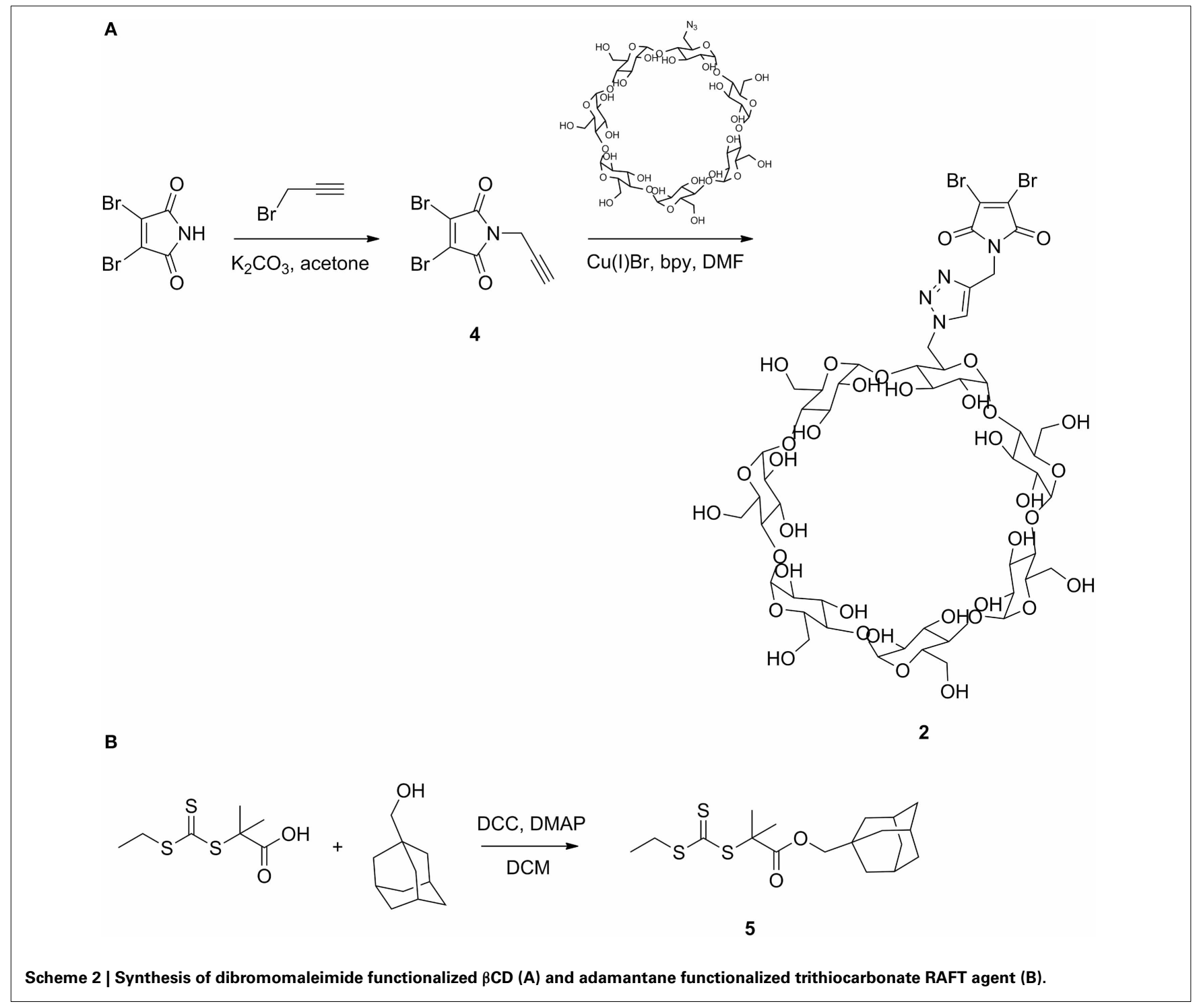


conditions, approximately $91.8 \%$ of the PNIPAM can be attached to the proteins (see calculation details in Supplementary Materials and Supplementary Figure 7). The high-frequency plateau modulus $\left(G^{\prime}\right.$ at $\left.100 \mathrm{rad} / \mathrm{s}\right)$ of the hybrid gel is $10 \mathrm{kPa}$ larger than the unmodified gel, and it increases moderately with increasing temperature, with a peak value at around $28^{\circ} \mathrm{C}$. The entanglement modulus also increases from 2030 to $3670 \mathrm{~Pa}$. The enhancement in the both moduli might originate from changes of protein architecture, and the formation of nanostructure within the gel due to segregation between the PNIPAM domain and the protein domain. Such microphase separation may even exist at low temperature, as enhancement in moduli is observed as low as $5^{\circ} \mathrm{C}$. This observation is consistent with the previous finding that PNIPAM segregation takes place even when the polymers are highly solvated (Glassman and Olsen, 2013).

\section{INFLUENCE OF BRANCHED ARCHITECTURE ON THE MECHANICAL PROPERTIES}

Branched polymers have attracted much interest for fundamental studies and industrial applications due to their distinct flow behaviors compared to their linear analogs (Dealy and Wissbrun, 1990; Janzen and Colby, 1999; Wood-Adams and Costeux, 2001; Lohse et al., 2002; Graessley, 2008; Wang et al., 2010b). However, few reports characterize the synthesis or properties of branched proteins, using either chemical methods or cellular machinery (Zhang et al., 2013). Here, branched proteins are synthesized with the use of multifunctional crosslinkers in the chain extension reaction, demonstrating an important means to control the mechanical properties of protein gels by modulating the chain structure. The effect of branching is examined by varying the fraction of the trifunctional crosslinker (2,4,6-triallyloxy-1,3,5triazine, 6) from 0 to $100 \%$ in the total alkenes (note that the ratio of total alkenes to thiols is kept 1:1). The hydrogels are prepared by thiol-ene click chemistry via thermal initiation. Similar to chain extension, all branching reactions are found to reach high endgroup conversion, yielding significant fractions of high molar mass proteins from SDS-PAGE (Figure 5). Significant differences in molecular weight distribution of proteins among the 6 reactions examined cannot be measured by gel electrophoresis. An exception occurs at $100 \%$ triene, where a larger fraction of low molar mass protein is present, suggesting that the endgroup conversion might be lower than those in other cases. All protein hydrogels are able to be dissolved in $6 \mathrm{M}$ urea buffer post reaction, confirming the hypothesis that addition of 6 only results in branching and not crosslinking, even with $100 \%$ triene crosslinker. The gel point under each reaction condition can be calculated using the Carothers equation or the Flory-Stockmayer theory (see calculation details in Supplementary Materials and Supplementary Figure 8), which shows great dependence on the triene composition. The solubility of gels in urea suggests that the conversion of the endgroups is below the gel point in all cases.

The mechanical properties of hydrogels are influenced by the branched structure of the proteins. To better compare the entire relaxation spectra with different fractions of $\mathbf{6}$, rheology data from creep experiments are converted to the dynamic compliance $J^{\prime}$ and $J^{\prime \prime}$ using a Fourier transform (Ferry, 1980),

$$
\begin{array}{r}
J^{\prime}(\omega)=J_{e}^{0}-\omega \int_{0}^{\omega}\left[J_{e}^{0}-J(t)+t / \eta_{0}\right] \sin \omega t d t \\
J^{\prime \prime}(\omega)=1 / \omega \eta_{0}+\omega \int_{0}^{\omega}\left[J_{e}^{0}-J(t)+t / \eta_{0}\right] \cos \omega t d t
\end{array}
$$

A

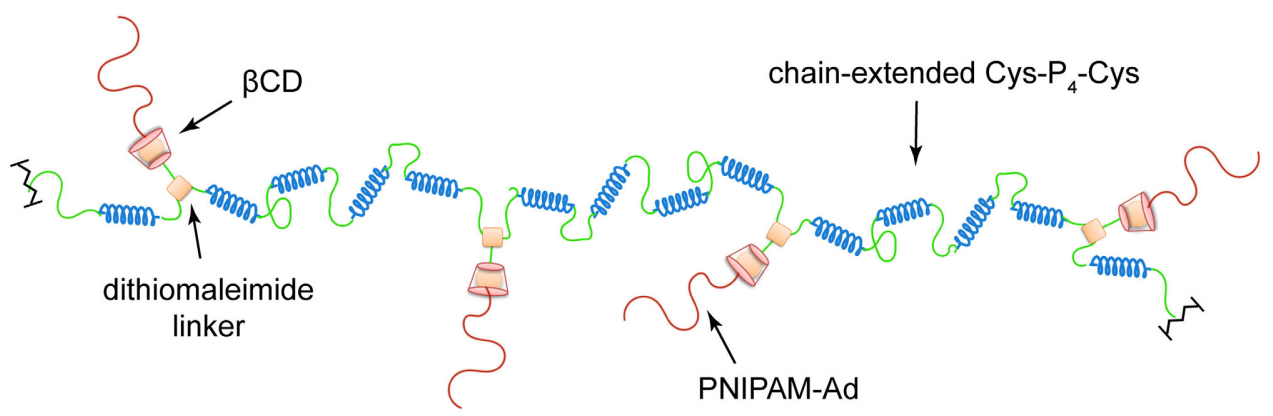

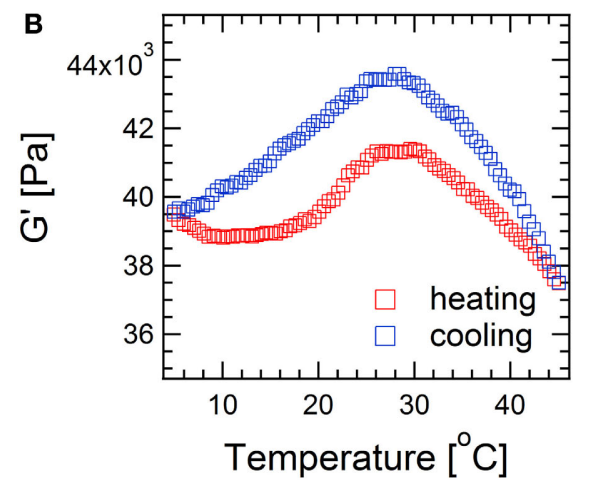

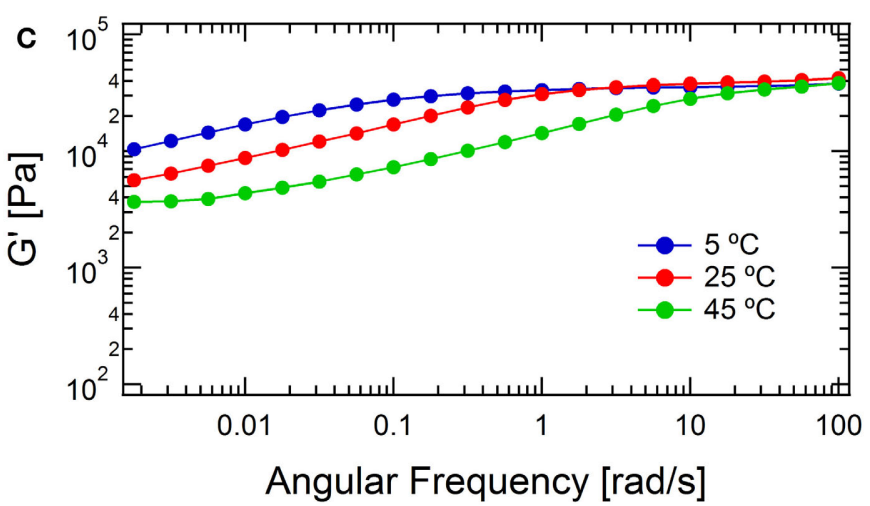

FIGURE 4 | Structure and mechanics of hybrid protein hydrogel. (A) Illustration of the brush-like structure of PNIPAM-extended-P 4 chimeric molecule formed via $\beta C D$-adamantane complexation; (B) Temperature sweep at $1^{\circ} \mathrm{C} / \mathrm{min}$ heating/cooling rate; (C) Frequency sweep spectra. 


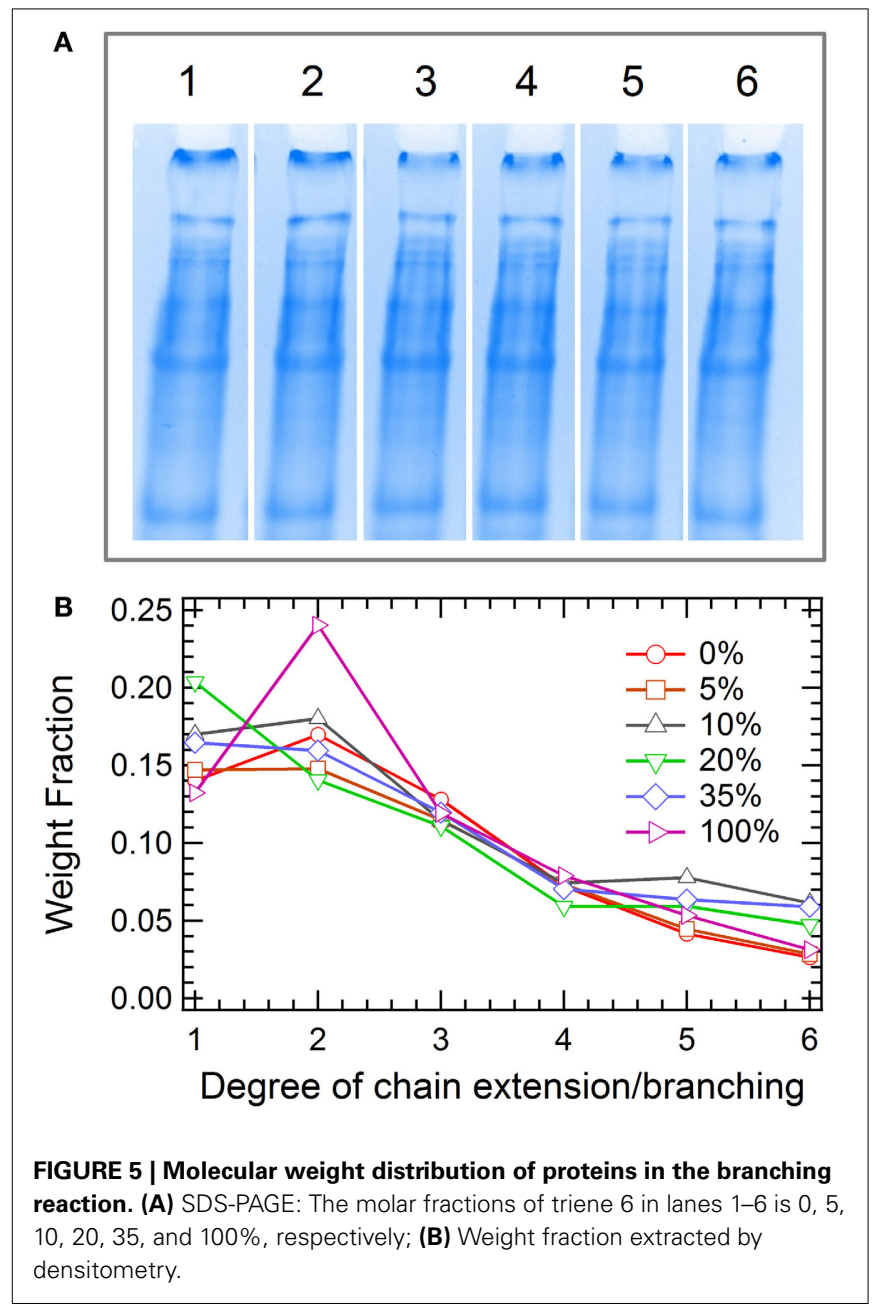

where $J_{e}^{0}$ is the recoverable compliance, $\omega$ the angular frequency, $\eta_{0}$ the zero-shear-rate viscosity, $t$ the experiment time. $J_{e}^{0}$ and $\eta_{0}$ are the intercept and the inverse of the slope, respectively, from a linear fit in steady-state phase of creep. The dynamic compliances are further translated into dynamic moduli $G^{\prime}$ and $G^{\prime \prime}$,

$$
\begin{aligned}
G^{\prime} & =J^{\prime} /\left(J^{\prime 2}+J^{\prime \prime 2}\right) \\
G^{\prime \prime} & =J^{\prime \prime} /\left(J^{\prime 2}+J^{\prime \prime 2}\right)
\end{aligned}
$$

The combined master curves are shown in Figure 6, which can be divided into three different regimes according to the relaxations present in the gels (from fast to slow): the coiled-coil regime, the entanglement regime and the terminal regime. With addition of a small amount of 6 (5 and 10\%), both the high-frequency modulus $\left(G_{\infty}^{\prime}\right)$ and the entanglement modulus $\left(G_{e}\right)$ decrease. This suggests that adding a small amount of crosslinker only causes short chain branching and small drops in the backbone length of the chain-extended proteins, since this would result in a decrease in the total number of entanglements. However, at $20 \%$ triene, both $G_{\infty}^{\prime}$ and $G_{e}$ reach their peak values, where the number density of the branch points and the branch length reach an optimal combination. In this case, the backbone length of the protein is likely to be comparable to the linear case, as the molecular weight distributions from SDS-PAGE of these two cases are not distinguishable, but the branched structure provides extra topological interactions. The introduced branches retard the reptation of the entire molecule, as it is only after arm retraction that the reptation of the chain-extended backbone is allowed to happen (Mcleish, 2002). Although the coiled-coil relaxation is only slightly affected by the molecule topology (see Supplementary Figures 9,10 ), the reptation regime broadens in the frequency spectrum and extends toward the low frequency regime. This
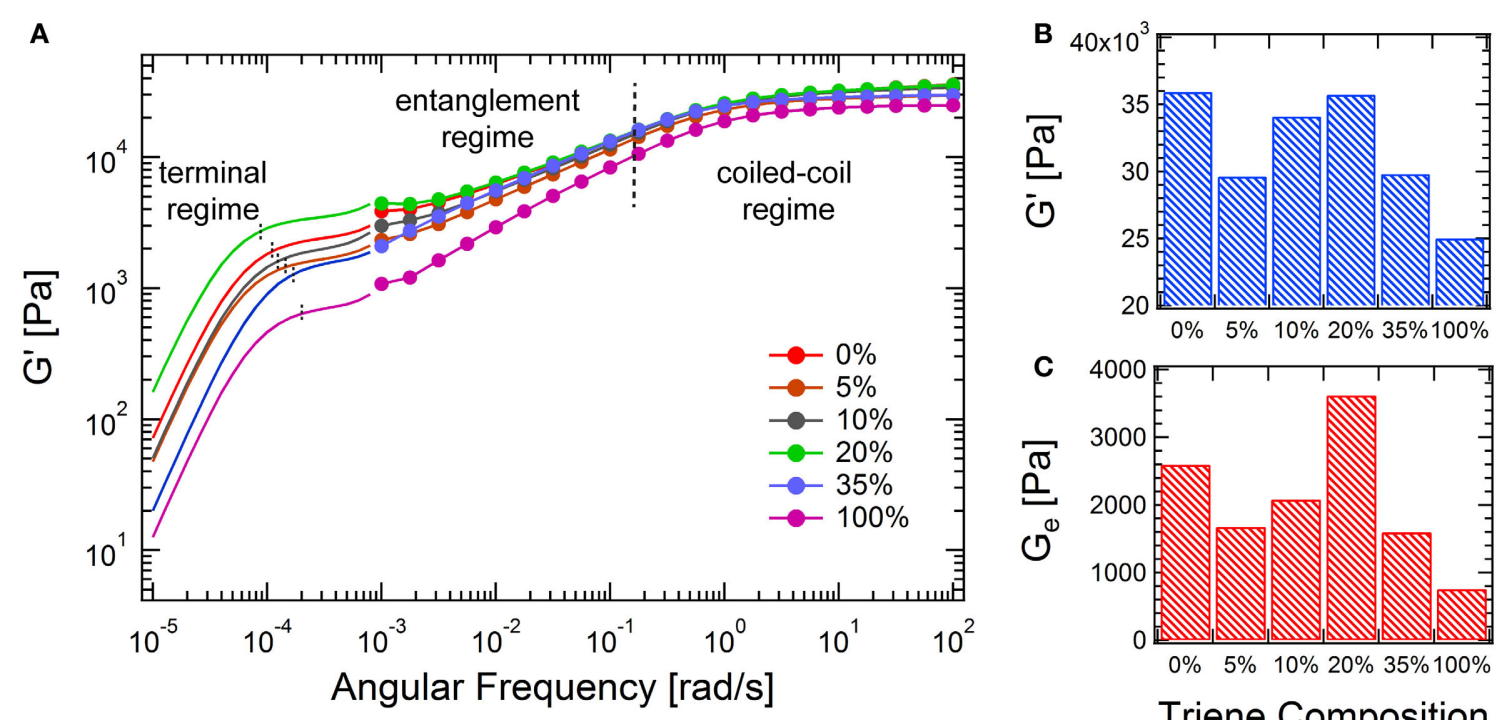

Triene Composition

FIGURE 6 | Comparison of the mechanical properties of branched hydrogels at different triene compositions. (A) Master curves at $25^{\circ} \mathrm{C}$ from oscillatory shear and creep experiments;
(B) comparison of the high-frequency moduli; (C) comparison of the entanglement moduli, determined from the converted low-frequency plateau. 
is consistent with the observation of randomly branched polymers in the melt state (Mcleish, 2002). Further increase of the triene composition leads to decreases in both $G_{\infty}^{\prime}$ and $G_{e}$. This is hypothesized to originate from the decreased engroup conversion and the formation of hyperbranched molecular structures. The densely packed branches impose permanent topological barriers for different chains to entangle, which leads to much lower solution viscosities (Voit and Lederer, 2009). Recently, the viscoelasticity and the dynamic relaxation of the synthetic hydrogels is found to be essential to mimic the complex biological tissues (Mckinnon et al., 2013). The presented branching reaction in this study establishes a facile approach of tuning the network mechanics over the entire frequency window, especially in the long time relaxation, which can be useful in mimicking the properties of natural tissues.

\section{CONCLUSION}

Under appropriate conditions, thiol-maleimide, thiol-bromomaleimide and thiol-ene coupling can all result in significant chain extension. The differences in chemistries' reactivity and side reactions may cause variations in the molecular weight and its distribution of chain-extended proteins and the topological entanglement effect in gels. While thiol-maleimide conjugation is the most common and the easiest to implement, thiol-ene click chemistry can achieve high endgroup conversion fairly rapidly. Thiol-bromomaleimide shows its potential in reversibly modifying proteins, and using functionalized dibromomaleimide as a chain extender allows further control of hydrogels' properties by incorporating side chain functionalities into the protein architecture. Here, thermoresponsive changes in mechanical properties of gels are demonstrated with PNIPAM grafts. Lastly, branched proteins are prepared in $\mathrm{A}_{2}+\mathrm{B}_{2} / \mathrm{B}_{3}$ mixed type reactions. The entanglement plateau modulus is increased when branches are long enough to enhance topological constraints yet the added branches do not sacrifice the backbone length. In conclusion, the structure of engineered proteins and their assembly behaviors can be easily modified with the use of different chemistries, which presents a rich toolbox to tailor the structure-properties of protein materials in various applications.

\section{ACKNOWLEDGMENTS}

This research was supported by the U.S. Army Research Office through the Institute of Soldier Nanotechnologies under contract W911NF-07-D-0004. The authors would like to acknowledge Krystyn Van Vliet and Gareth McKinley for the use of rheometers, Alexander Babarti for providing training on the MCR 702 rheometer, and Muzhou Wang for assistance with FPLC.

\section{SUPPLEMENTARY MATERIAL}

The Supplementary Material for this article can be found online at: http://www.frontiersin.org/journal/10.3389/fchem.2014. 00023/abstract

\section{REFERENCES}

Baldwin, A. D., and Kiick, K. L. (2011). Tunable degradation of maleimidethiol adducts in reducing environments. Bioconjug. Chem. 22, 1946-1953. doi: $10.1021 / \mathrm{bc} 200148 \mathrm{v}$

Canalle, L. A., Lowik, D. W. P. M., and Van Hest, J. C. M. (2010). Polypeptidepolymer bioconjugates. Chem. Soc. Rev. 39, 329-353. doi: 10.1039/b807871 h
Chung, C., Lampe, K. J., and Heilshorn, S. C. (2012). Tetrakis(hydroxymethyl) phosphonium chloride as a covalent cross-linking agent for cell encapsulation within protein-based hydrogels. Biomacromolecules 13, 3912-3916. doi: 10.1021/bm3015279

Convertine, A. J., Lokitz, B. S., Vasileva, Y., Myrick, L. J., Scales, C. W., Lowe, A. B., et al. (2006). Direct synthesis of thermally responsive DMA/NIPAM Diblock and DMA/NIPAM/DMA triblock copolymers via aqueous, room temperature RAFT Polymerization $\dagger$. Macromolecules 39, 1724-1730. doi: $10.1021 / \mathrm{ma} 0523419$

Cui, Y., Yan, Y., Chen, Y., and Wang, Z. (2013). Dibromomaleimide derivative as an efficient polymer coupling agent for building topological polymers. Macromol. Chem. Phys. 214, 470-477. doi: 10.1002/macp.201200614

Davis, M. E., and Brewster, M. E. (2004). Cyclodextrin-based pharmaceutics: past, present and future. Nat. Rev. Drug Discov. 3, 1023-1035. doi: 10.1038/nrd1576

Davis, N. E., Ding, S., Forster, R. E., Pinkas, D. M., and Barron, A. E. (2010). Modular enzymatically crosslinked protein polymer hydrogels for in situ gelation. Biomaterials 31, 7288-7297. doi: 10.1016/j.biomaterials.2010.06.003

Dealy, J. M., and Wissbrun, K. F. (1990). Melt Rheology and Its Role in Plastics Processing: Theory and Applications. New York, NY: Van Nostrand Reinhold.

Dondoni, A., Massi, A., Nanni, P., and Roda, A. (2009). A new ligation strategy for peptide and protein glycosylation: photoinduced thiol-ene coupling. Chem. Eur. J. 15, 11444-11449. doi: 10.1002/chem.200901746

Drury, J. L., and Mooney, D. J. (2003). Hydrogels for tissue engineering: scaffold design variables and applications. Biomaterials 24, 4337-4351. doi: 10.1016/S0142-9612(03)00340-5

Dutton, S., Rolfes, H., and Stepto, R. F. T. (1994). Comparison of ahmad-rolfesstepto theory, rate theory and monte-carlo modelling of gel point and network modulus. Polymer 35, 4521-4526. doi: 10.1016/0032-3861(94)90797-8

Ferry, J. (1980). Viscoelastic Properties of Polymers. New York, NY: Wiley.

Glassman, M. J., Chan, J., and Olsen, B. D. (2013). Reinforcement of shear thinning protein hydrogels by responsive block copolymer self-assembly. Adv. Funct. Mater. 23, 1182-1193. doi: 10.1002/adfm.201202034

Glassman, M. J., and Olsen, B. D. (2013). Structure and mechanical response of protein hydrogels reinforced by block copolymer self-assembly. Soft Matt. 9, 6814-6823. doi: 10.1039/c3sm00102d

Gong, J. P., Katsuyama, Y., Kurokawa, T., and Osada, Y. (2003). Double-network hydrogels with extremely high mechanical strength. Adv. Mater. 15, 1155-1158. doi: 10.1002/adma.200304907

Graessley, W. W. (2004). Polymeric Liquids and Networks: Structure and Properties. New York, NY: Garland Science.

Graessley, W. W. (2008). Polymeric Liquids and Networks: Dynamics and Rheology. London; New York: Garland Science.

Guvendiren, M., Lu, H. D., and Burdick, J. A. (2012). Shear-thinning hydrogels for biomedical applications. Soft Matt. 8, 260-272. doi: 10.1039/c1sm06513k

Haraguchi, K., and Takehisa, T. (2002). Nanocomposite Hydrogels: a unique organic-inorganic network structure with extraordinary mechanical, optical, and swelling/de-swelling properties. Adv. Mater. 14, 1120-1124. doi: 10.1002/1521-4095(20020816)14:16<1120::AID-ADMA1120>3.0.CO;2-9

Harries, D., Rau, D. C., and Parsegian, V. A. (2005). Solutes probe hydration in specific association of cyclodextrin and adamantane. J. Am. Chem. Soc. 127, 2184-2190. doi: 10.1021/ja045541t

Hermanson, G. T. (2008). Bioconjugate Techniques, 2nd Edn. Amsterdam: Elsevier. Holten-Andersen, N., Harrington, M. J., Birkedal, H., Lee, B. P., Messersmith, P. B., Lee, K. Y. C., et al. (2011). pH-induced metal-ligand cross-links inspired by mussel yield self-healing polymer networks with near-covalent elastic moduli. Proc. Natl. Acad. Sci. U.S.A. 108, 2651-2655. doi: 10.1073/pnas.1015862108

Hoyle, C. E., and Bowman, C. N. (2010). Thiol-ene click chemistry. Angewandte Chem. Int. Ed. 49, 1540-1573. doi: 10.1002/anie.200903924

Hoyle, C. E., Lowe, A. B., and Bowman, C. N. (2010). Thiol-click chemistry: a multifaceted toolbox for small molecule and polymer synthesis. Chem. Soc. Rev. 39, 1355-1387. doi: 10.1039/b901979k

Janzen, J., and Colby, R. H. (1999). Diagnosing long-chain branching in polyethylenes. J. Mol. Struct. 485-486, 569-584. doi: 10.1016/S0022-2860(99) 00097-6

Jing, P., Rudra, J. S., Herr, A. B., and Collier, J. H. (2008). Self-assembling peptide-polymer hydrogels designed from the coiled coil region of fibrin. Biomacromolecules 9, 2438-2446. doi: 10.1021/bm800459v

Jones, M. W., Strickland, R. A., Schumacher, F. F., Caddick, S., Baker, J. R., Gibson, M. I., et al. (2011). Polymeric dibromomaleimides as extremely efficient 
disulfide bridging bioconjugation and pegylation agents. J. Am. Chem. Soc. 134, 1847-1852. doi: 10.1021/ja210335f

Kim, M., Tang, S., and Olsen, B. D. (2013). Physics of engineered protein hydrogels. J. Polymer Sci. B Polymer Phys. 51, 587-601. doi: 10.1002/polb.23270

Kloxin, A. M., Kasko, A. M., Salinas, C. N., and Anseth, K. S. (2009). Photodegradable hydrogels for dynamic tuning of physical and chemical properties. Science 324, 59-63. doi: 10.1126/science.1169494

Lai, J. T., Filla, D., and Shea, R. (2002). Functional polymers from novel carboxylterminated trithiocarbonates as highly efficient RAFT agents. Macromolecules 35, 6754-6756. doi: $10.1021 / \mathrm{ma} 020362 \mathrm{~m}$

Larson, R. G., Sridhar, T., Leal, L. G., Mckinley, G. H., Likhtman, A. E., and Mcleish, T. C. B. (2003). Definitions of entanglement spacing and time constants in the tube model. J. Rheol. 47, 809-818. doi: 10.1122/1.1567750

Li, L., Teller, S., Clifton, R. J., Jia, X., and Kiick, K. L. (2011). Tunable mechanical stability and deformation response of a resilin-based elastomer. Biomacromolecules 12, 2302-2310. doi: 10.1021/bm200373p

Lohse, D. J., Milner, S. T., Fetters, L. J., Xenidou, M., Hadjichristidis, N., Mendelson, R. A., et al. (2002). Well-defined, model long chain branched Polyethylene. 2. Melt rheological behavior. Macromolecules 35, 3066-3075. doi: $10.1021 / \mathrm{ma} 0117559$

Lv, S., Dudek, D. M., Cao, Y., Balamurali, M. M., Gosline, J., and Li, H. (2010). Designed biomaterials to mimic the mechanical properties of muscles. Nature 465, 69-73. doi: 10.1038/nature09024

Mckinnon, D. D., Domaille, D. W., Cha, J. N., and Anseth, K. S. (2013). Biophysically defined and cytocompatible covalently adaptable networks as Viscoelastic 3D cell culture systems. Adv. Mater. 26, 865-872. doi: 10.1002/adma.201303680

Mcleish, T. C. B. (2002). Tube theory of entangled polymer dynamics. Adv. Phys. 51, 1379-1527. doi: 10.1080/00018730210153216

Nathani, R. I., Chudasama, V., Ryan, C. P., Moody, P. R., Morgan, R. E., Fitzmaurice, R. J., et al. (2013). Reversible protein affinity-labelling using bromomaleimidebased reagents. Org. Biomol. Chem. 11, 2408-2411. doi: 10.1039/c3ob40239h

Northrop, B. H., and Coffey, R. N. (2012). Thiol-ene click chemistry: computational and kinetic analysis of the influence of alkene functionality. J. Am. Chem. Soc. 134, 13804-13817. doi: 10.1021/ja305441d

Petter, R. C., Salek, J. S., Sikorski, C. T., Kumaravel, G., and Lin, F. T. (1990). Cooperative binding by aggregated mono-6-(alkylamino)-.beta.-cyclodextrins. J. Am. Chem. Soc. 112, 3860-3868. doi: 10.1021/ja00166a021

Rekharsky, M. V., and Inoue, Y. (1998). Complexation thermodynamics of cyclodextrins. Chem. Rev. 98, 1875-1918. doi: 10.1021/cr970015o

Robin, M. P., Wilson, P., Mabire, A. B., Kiviaho, J. K., Raymond, J. E., Haddleton, D. M., et al. (2013). Conjugation-induced fluorescent labeling of proteins and polymers using dithiomaleimides. J. Am. Chem. Soc. 135, 2875-2878. doi: 10.1021/ja3105494

Ryan, C. P., Smith, M. E. B., Schumacher, F. F., Grohmann, D., Papaioannou, D., Waksman, G., et al. (2011). Tunable reagents for multi-functional bioconjugation: reversible or permanent chemical modification of proteins and peptides by control of maleimide hydrolysis. Chem. Commun. 47, 5452-5454. doi: $10.1039 / \mathrm{clccl} 1114 \mathrm{k}$

Sahin, E., and Kiick, K. L. (2009). Macromolecule-induced assembly of coiledcoils in alternating multiblock polymers. Biomacromolecules 10, 2740-2749. doi: $10.1021 / \mathrm{bm} 900474 \mathrm{k}$

Schelté, P., Boeckler, C., Frisch, B., and Schuber, F. (1999). Differential reactivity of maleimide and bromoacetyl functions with thiols: application to the preparation of liposomal diepitope constructs. Bioconjug. Chem. 11, 118-123. doi: $10.1021 / \mathrm{bc} 990122 \mathrm{k}$

Schöneich, C. (2008). Mechanisms of protein damage induced by cysteine thiyl radical formation. Chem. Res. Toxicol. 21, 1175-1179. doi: 10.1021/tx800005u

Shen, W., Lammertink, R. G. H., Sakata, J. K., Kornfield, J. A., and Tirrell, D. A. (2005). Assembly of an artificial protein hydrogel through leucine zipper aggregation and disulfide bond formation. Macromolecules 38, 3909-3916. doi: 10.1021/ma048348s

Smith, M. E. B., Schumacher, F. F., Ryan, C. P., Tedaldi, L. M., Papaioannou, D., Waksman, G., et al. (2010). Protein modification, bioconjugation, and disulfide bridging using bromomaleimides. J. Am. Chem. Soc. 132, 1960-1965. doi: $10.1021 /$ ja908610s
Stephanopoulos, N., and Francis, M. B. (2011). Choosing an effective protein bioconjugation strategy. Nat. Chem. Biol. 7, 876-884. doi: 10.1038/nchem bio. 720

Sun, J.-Y., Zhao, X., Illeperuma, W. R. K., Chaudhuri, O., Oh, K. H., Mooney, D. J., et al. (2012). Highly stretchable and tough hydrogels. Nature 489, 133-136. doi: $10.1038 /$ nature 1409

Tanaka, F. (2011). Polymer Physics: Applications to Molecular Association and Thermoreversible Gelation. Cambridge: Cambridge University Press. doi: 10.1017/CBO9780511975691

Tang, S., Glassman, M. J., Li, S., Socrate, S., and Olsen, B. D. (2014). Oxidatively responsive chain extension to entangle engineered protein hydrogels. Macromolecules 47, 791-799. doi: 10.1021/ma401684w

Trabbic-Carlson, K., Setton, L. A., and Chilkoti, A. (2003). Swelling and mechanical behaviors of chemically cross-linked hydrogels of elastin-like polypeptides. Biomacromolecules 4, 572-580. doi: 10.1021/bm025671z

Valkevich, E. M., Guenette, R. G., Sanchez, N. A., Chen, Y.-C., Ge, Y., and Strieter, E. R. (2012). Forging isopeptide bonds using thiol-ene chemistry: site-specific coupling of ubiquitin molecules for studying the activity of isopeptidases. J. Am. Chem. Soc. 134, 6916-6919. doi: 10.1021/ja300500a

Voit, B. I., and Lederer, A. (2009). Hyperbranched and highly branched polymer architectures-synthetic strategies and major characterization aspects. Chem. Rev. 109, 5924-5973. doi: 10.1021/cr900068q

Wan, Q., and Danishefsky, S. J. (2007). Free-radical-based, specific desulfurization of cysteine: a powerful advance in the synthesis of polypeptides and glycopolypeptides. Angewandte Chem. Int. Ed. 46, 9248-9252. doi: 10.1002/anie.200704195

Wang, Q., Mynar, J. L., Yoshida, M., Lee, E., Lee, M., Okuro, K., et al. (2010a). Highwater-content mouldable hydrogels by mixing clay and a dendritic molecular binder. Nature 463, 339-343. doi: 10.1038/nature08693

Wang, Z., Chen, X., and Larson, R. G. (2010b). Comparing tube models for predicting the linear rheology of branched polymer melts. J. Rheol. (1978-present) 54, 223-260. doi: 10.1122/1.3301246

Weinrich, D., Lin, P.-C., Jonkheijm, P., Nguyen, U. T. T., Schröder, H., Niemeyer, C. M., et al. (2010). Oriented immobilization of farnesylated proteins by the thiol-ene reaction. Angewandte Chem. Int. Ed. 49, 1252-1257. doi: 10.1002/anie.200906190

Wood-Adams, P., and Costeux, S. (2001). Thermorheological behavior of polyethylene: effects of microstructure and long chain branching. Macromolecules 34, 6281-6290. doi: 10.1021/ma0017034

Wu, L. C., Yang, J., and Kopeček, J. (2011). Hybrid hydrogels selfassembled from graft copolymers containing complementary $\beta$-sheets as hydroxyapatite nucleation scaffolds. Biomaterials 32, 5341-5353. doi: 10.1016/j.biomaterials.2011.04.014

Zhang, W.-B., Sun, F., Tirrell, D. A., and Arnold, F. H. (2013). Controlling macromolecular topology with genetically encoded spytag-spycatcher chemistry. J. Am. Chem. Soc. 135, 13988-13997. doi: 10.1021/ja4076452

Zhou, H., Woo, J., Cok, A. M., Wang, M., Olsen, B. D., and Johnson, J. A. (2012). Counting primary loops in polymer gels. Proc. Natl. Acad. Sci. U.S.A. 109, 19119-19124. doi: 10.1073/pnas.1213169109

Conflict of Interest Statement: The authors declare that the research was conducted in the absence of any commercial or financial relationships that could be construed as a potential conflict of interest.

Received: 03 March 2014; accepted: 22 April 2014; published online: 14 May 2014. Citation: Tang S and Olsen BD (2014) Controlling topological entanglement in engineered protein hydrogels with a variety of thiol coupling chemistries. Front. Chem. 2:23. doi: $10.3389 /$ fchem.2014.00023

This article was submitted to Chemical Biology, a section of the journal Frontiers in Chemistry.

Copyright $\odot 2014$ Tang and Olsen. This is an open-access article distributed under the terms of the Creative Commons Attribution License (CC BY). The use, distribution or reproduction in other forums is permitted, provided the original author(s) or licensor are credited and that the original publication in this journal is cited, in accordance with accepted academic practice. No use, distribution or reproduction is permitted which does not comply with these terms. 